\title{
STUDY OF THE INFLUENCE OF MICELLAR CASEIN AND SPELT FLOUR ON YOGHURT QUALITY INDICATORS
}

\author{
Galyna Polischuk \\ Department of Technology of Milk and Dairy Products \\ E-mail:milknuft@i.ua
}

Nataliia Breus

Department of Informatics ${ }^{1}$

Oxana Kochubey-Litvinenko

Department of Technology of Milk and Dairy Products

Tetiana Osmak

Department of Technology of Milk and Dairy Products ${ }^{1}$

Tetiana Semko

Department of Tourism, Hotel and Restaurant Business Vinnytsia Institute of Trade and Economics of Kyiv National University of

Trade and Economics University

87 Soborna str., Ukraine, Vinnytsia, 21050

\author{
Marina Borova \\ Department of Technology of Milk and Dairy Products1
}

${ }^{1}$ National University of Food Technologies

68 Volodymyrska str., Kyiv, Ukraine, 01033

\begin{abstract}
The aim of the research is to study the effect of protein-containing ingredients of animal and plant origin on the quality indicators of yoghurt for the scientific substantiation of its recipe composition. Micellar casein and spelled flour are characterized by high nutritional value, exhibit functional and technological properties and can significantly affect the quality indicators of yogurt. To confirm this, the possibility of complete replacement of the structure stabilizer in the composition of yoghurt with micellar casein and spelled flour, both separately and in various ratios, was studied. As a single criterion for optimizing the recipe composition of yoghurt at various ratios between casein and spelled flour, product quality indicators were used: the degree of syneresis, effective viscosity, organoleptic indicators. The optimal values of the single criteria were obtained at different ranges of ratios between natural ingredients, which don't allow developing uniform recommendations for the formulation of a new type of yogurt. Therefore, to study the combined effect of protein and spelled flour on the characteristics of yoghurt and the coefficients of their significance, a complex quality indicator was used. This indicator was determined as a function of estimates of single quality indicators, converted to scaled values, taking into account the coefficients of significance of individual indicators. Using a complex quality indicator, the ranges of optimal values of the content of micellar casein and spelled flour in yoghurt were established. So, when adding casein in an amount of 1.25 to $3.0 \%$ and spelled flour - from 0.75 to $1.50 \%$, the quality of yoghurt reached its maximum value. The use of these ingredients alone showed a significantly lower technological effect in comparison with their compositions. Therefore, a conclusion was made about the synergistic interaction of casein and spelled flour, as well as the advisability of using the compositional composition of these ingredients in the yogurt technology.
\end{abstract}

Keywords: yogurt, micellar casein, spelled, optimization of the composition, comprehensive quality indicator.

DOI: $10.21303 / 2504-5695.2020 .001378$

\section{Introduction}

The increased demand for yoghurts is forcing manufacturers to improve existing technologies by developing and introducing more and more progressive ways of making it, as well as using innovative ingredients. In the production of fermented milk drinks, one of the main processes that affect their quality indicators is the formation of a clot. The dense curd characteristic of yoghurt can be obtained only by using high-quality milk with a high solids' content in combination with 
stabilizers or skimmed milk powder [1]. These ingredients reduce syneresis due to the moisture binding capacity and, thus, preserve the consumption properties of the product until the moment of its sale [2]. However, structure stabilizers, used in modern technologies, do not have a nutritional value, and skimmed milk powder is not efficient enough from a technological point of view. At the same time, natural ingredients, containing food biopolymers, can perform multipurpose functions in yoghurt, including replacing stabilizers and milk powder. In this regard, the aim of the rsearch is to study the effect of micellar casein and spelled flour on the quality indicators of yoghurt for the scientific substantiation of its recipe composition. To achieve this goal, the composition of the yoghurt was optimized using the response surface methodology using graphic 3D models. To study the joint effect of prescription ingredients on single quality indicators and their significance coefficients, a complex quality indicator was used.

\section{Problem status overview}

In order to increase the nutritional value of yoghurt, the physicochemical characteristics of a number of natural protein-containing ingredients were analyzed, which can exhibit technological activity and, as a result, replace the classical stabilizers of the structure. These ingredients can also increase the nutritional value of yoghurts due to the presence of biologically complete proteins, carbohydrates and fats containing polyunsaturated fatty acids. Thus, it was suggested, that spelled flour (Triticumspelta) can exhibit stabilizing properties in the composition of yoghurt due to its high protein content (from $15 \%$ and more) and starch (up to 52-54\%), which forms very small granules. Spelled starch swells well and effectively thickens food moisture-containing systems. Spelled flour is one of the leaders among food products in terms of protein content [3]. It also contains dietary fiber and minerals, balanced in micronutrient composition, which is an important point in the development of healthy foods. Spelled flour lipids contain more MUFA and PUFA, including $\dot{\omega}-3$ and $\dot{\omega}-6$ fatty acids, in comparison with wheat flour [4]. Spelled flour contains more vitamins and minerals, in comparison with wheat, due to its specific feature to absorb more nutrients from the soil $[5,6]$.

Among milk-protein concentrates, from the technological feasibility point of view, micellar casein deserves the greatest attention. This concentrate contains native protein, which is obtained by micro- and ultrafiltration from skim milk [7]. This protein is characterized by a high level of digestibility, is highly soluble in water, exhibits emulsifying properties and has excellent organoleptic characteristics. Various brands of micellar casein contain from 70.0 to $85.5 \%$ protein [8].

Thus, the use of spelled flour and micellar casein in yoghurt requires scientific research, since these ingredients can exhibit special functional and technological properties and significantly affect the quality indicators of the finished product.

\section{Materials and Methods}

To substantiate the requirements for physical, chemical and organoleptic indicators, we used those for yoghurt with a mass fraction of $1.5 \%$ fat, which contains modified starch. For the study, samples of yoghurt with a mass fraction of $1.5 \%$ fat were prepared with complete replacement of casein-modified starch with micellar, spelled flour and their combinations in various ratios.

To enrich the yogurt and form a characteristic thick consistency, micellar casein with a mass fraction of $80 \%$ protein of Willmax 80 brand (manufactured by LLC "Gadyachsir", Ukraine) and flour from organic spelled (spelled) (manufactured by Private Enterprise "Organic Eco Product", Ukraine) were used.

Samples of yoghurt were obtained in laboratory conditions in accordance with the classical production flow chart. To improve the hydration process, micellar casein and spelled flour were pre-mixed. A mixture of dry ingredients was introduced into milk normalized in terms of fat content at a temperature of $40-45^{\circ} \mathrm{C}$. Pasteurization of the milk mixture was carried out in a periodic way at a temperature of $92 \pm 2{ }^{\circ} \mathrm{C}$ for 5 minutes. At the pasteurization temperature, the mixture was subjected to homogenization under a pressure at the first stage of $12.5 \pm 0.5 \mathrm{MPa}$ and $4.0 \pm 0.5 \mathrm{MPa}$ at the second stage. The homogenized mixture was cooled to a temperature of 
$39 \pm 2{ }^{\circ} \mathrm{C}$, a leaven of TM "VIVO" (Ukraine) was added, containing thermophilic lactic acid microflora (Streptococcus thermophilus, Lactobacillus delbrueckii ssp. Bulgaricus, Lactobacillus acidophilus was milled to less than $80^{\circ} \mathrm{C}$ ) $\mathrm{pH}=4.7$ ). The yoghurt samples were cooled and stored in a refrigerating chamber at a temperature of $(4 \pm 2){ }^{\circ} \mathrm{C}$ for at least 8 days, after which they were examined.

Recipe components mixing and pasteurization of milk mixtures was carried out using a Thermomix VORWERK laboratory mixer. The model mixtures were homogenized using a laboratory homogenizer-disperser model 15M-8TA "Lab Homogenizer \& Sub-Micron Disperser" (GAULIN CORPORATION, Massachusetts, USA). The studies used a model with a two-stage valve device. The technical characteristics of the homogenizer-dispersant are as follows:

- overall dimensions, $\mathrm{mm}-840 \times 930 \times 700$;

- productivity $57 \mathrm{dm}^{3} /$ hour; maximum pressure - $25 \mathrm{MPa}$;

- the minimum volume of a test sample is $200 \mathrm{~cm}^{3}$;

The appearance of the specified equipment is shown in Fig. 1.

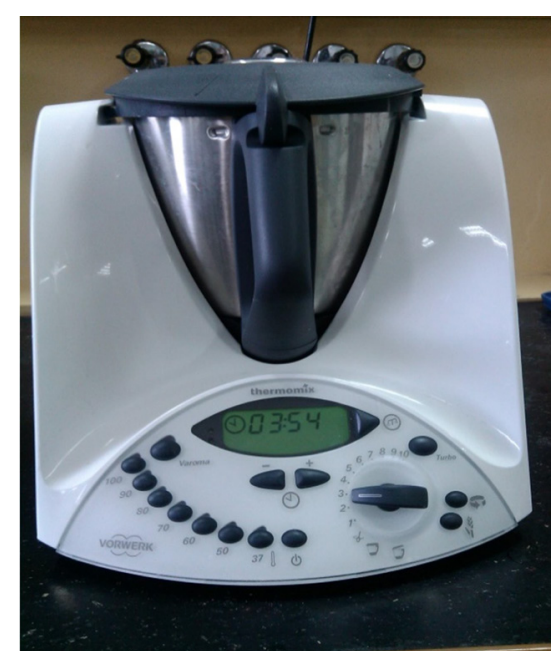

$a$

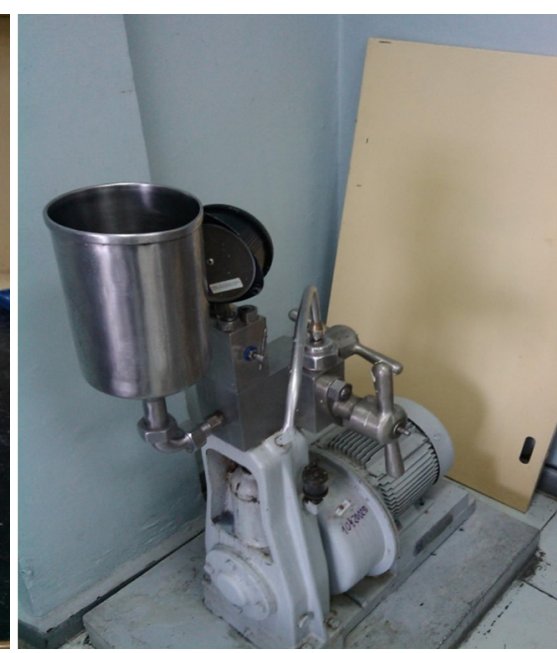

$b$

Fig. 1. Thermomix VORWERK mixer $(a)$ and

homogenizer-dispersant model 15M-8TA “Lab Homogenizer \& Sub-Micron Disperser” (b)

The acidity of yoghurt, expressed in Turner degrees $\left({ }^{\circ} \mathrm{T}\right)$, was determined by the titrimetric method [9].

The organoleptic characteristics of yogurt were determined on a 10-point scale in accordance with the requirements, presented in Table 1.

Table 1

Assessment of the quality of yoghurt samples by organoleptic indicators (maximum possible points are indicated)

\begin{tabular}{ll}
\hline Indicator name & Indicator characteristics
\end{tabular}

Consistency, appearance $(3$ points $*)$

Homogeneous, tender, with a disturbed or undisturbed clot, moderately thick, without gas formation, without noticeable inclusions of additives.

Taste and smell (6 points *)

Clean, fermented milk, without foreign tastes and odors. For yoghurt with toppings with pleasant additive flavor.

Color $(1$ point *)

White, for yoghurt with additives or fillers, is due to their color.

Note:* - the maximum possible points are indicated 
The effective viscosity of the experimental samples was determined using a "REOTEST II" rotary viscometer with a cylinder-cylinder measuring system by taking deformation (flow) curves at the temperature of $20^{\circ} \mathrm{C}$, according to the method, described in [10]. The measuring cylinder (rotor) S1 was chosen, so that the gradient layer was distributed over the entire thickness of the product layer, placed in the annular gap of the viscometer measuring device. The measurement of the shear stress $(\mathrm{Pa})$ was carried out at the first shear rate $(\gamma=3 s-1)$ with a forward stroke in order to reveal the rheological characteristics of the practically intact yoghurt structure.

The syneresis' degree (release of serum from yoghurt clots) was studied by the centrifugal method, described in [11] using a laboratory centrifuge Sigma 2-6E (Germany), at the rotation speed of $1000 \mathrm{rpm}$ centrifuge tubes with the volume of $25 \mathrm{~cm}^{3}$ for 20 minutes and recalculating the volume of released whey in $\mathrm{cm}^{3}$ per $100 \mathrm{~g}$ of the product.

The calculation of the optimal recipe composition of yogurt with micellar casein and spelled flour was carried out in the environment of the mathematical package MathCad 15. The existing models for optimizing the composition of the product were reduced to the task of regression analysis of experimental data by the method of multivariate approximation. The method used makes it possible to find the optimal values of the content of new ingredients in yoghurt, at which the specified physicochemical and organoleptic characteristics of the product quality are formed.

In order to optimize the response functions during the development of a new type of yoghurt with natural ingredients, the response surface methodology was applied using graphic 3D models [12]. In general, the response function is described by the polynomial (1):

$$
\hat{y}(x, b)=b_{0}+\sum_{l=1}^{n} b_{1} x_{1}+\sum_{k=1}^{n} b_{k} x_{k}^{2}+\sum_{i=1}^{n-1} \sum_{j=i+1}^{n} b_{i j} x_{i} x_{j},
$$

where $x \in R^{n}$ is a vector of variables, $b$ is a vector of parameters.

The following characteristics were used as criteria for optimizing the yogurt recipe composition:

- degree of syneresis $\left(S, \mathrm{~cm}^{3} / 100 \mathrm{~g}\right)$;

- effective viscosity of a practically intact system at a shear rate $\gamma=3 s-1(\eta, \mathrm{mPa} \cdot \mathrm{s})$;

- organoleptic indicators (OI, points).

For these criteria, the recommended values are typical for the control sample of the classical composition with skimmed milk powder:

- degree of syneresis - no more than $15 \mathrm{~cm}^{3} / 100 \mathrm{~g}$;

- effective viscosity - not less than $600 \mathrm{mPa} \cdot \mathrm{s}$;

- organoleptic indicators - from 9 to 10.9 points.

The independent variables that affect the optimization criteria are the mass fraction of micellar casein $(B, \%)$ in the range from 0 to $3 \%$ and the mass fraction of spelled flour $(F, \%)$ in the range from 0 to $3 \%$.

To study the combined effect of protein and spelled flour on individual quality indicators and coefficients of their significance, a complex quality indicator (CQI) was used. The complex indicator was determined as a function of estimates of single quality indicators, converted to scaled values, taking into account the coefficients of significance of individual indicators according to the formula (2):

$$
C Q I_{j}=\sum \sqrt[M]{\prod_{j=1}^{n} C Q I_{j}^{M_{j}}},
$$

where $M_{j}$ is the significance of the main characteristics $0 \leq M_{j} \leq 1$, a comprehensive quality indicator $1 \leq C Q_{j} \leq 10$.

For the experimental data, the following significance coefficients were adopted:

$-\mathrm{M}_{1}-$ degree of syneresis $(0.15)$;

$-M_{2}$ - effective viscosity (0.15);

$-\mathrm{M}_{3}$ - organoleptic indicators (0.70). 
Wherein:

$$
\sum_{j=1}^{n} M_{j}=1
$$

To convert the single indicators to the range from 1 to 10 , the initial data were scaled in accordance with the formula (4).

$$
y=\frac{\left(y_{\max }-y_{\min }\right) \cdot\left(x-x_{\min }\right)}{x_{\max }-x_{\min }}+y_{\min } .
$$

Modeling of the recipe composition of yoghurt was carried out under the influence of the input variable parameters (protein and spelled flour content in the specified ranges) on the output characteristics of the finished product (syneresis $-S$, effective viscosity $-E V$, organoleptic indicators $-O I)$.

The nature of the distribution of experimental points in the factor space indicates that the dependences can have the form of polynomials of the second degree (5)-(7):

$$
\begin{aligned}
& S=b_{0}+b_{1} M s+b_{11} M s^{2}+b_{2} M c+b_{22} M c^{2}+b_{12} M s M c, \\
& E V=b_{0}+b_{1} M s+b_{11} M s^{2}+b_{2} M c+b_{22} M c^{2}+b_{12} M s M c, \\
& O I=b_{0}+b_{1} M s+b_{11} M s^{2}+b_{2} M c+b_{22} M c^{2}+b_{12} M s M c,
\end{aligned}
$$

where $b$ is a constant; $M s$ - mass fraction of spelled, $\% ; M c$ - mass fraction of micellar casein, $\%$.

To estimate the unknown parameters $b_{0}, b_{1}, b_{2}$, the least squares method (OLS) was used. In accordance with this method, the unknown parameters of the function are selected, so that the sum of the squares of the deviations of the empirical values Yi from their calculated values is minimal:

$$
\begin{gathered}
S=\sum_{i=1}^{n}\left(Y_{i}-Y_{i p}\right)^{2}= \\
=\sum_{i=1}^{n}\left(Y_{i}-\varphi\left(X_{i}, b_{0}, b_{1}, \ldots, b_{k}\right)\right)^{2} \rightarrow \min .
\end{gathered}
$$

For research, there are two factors at four levels. In particular, the choice of four levels of values for the mass fraction of casein $(0,1,2,3 \%)$ is due to the fact that it is in this range of values that the milk protein used provides the structuring of the fermented milk curd characteristic of yogurt. It should also be noted that, as a rule, the content of casein in the composition of food products is in the range of about $2 \%$, that is, in the middle of the selected range.

The choice of four values of the mass fraction of spelled flour $(0,1,2,3 \%)$ is due to the fact that the recommended content of grain products in the composition of dairy products is usually in the proposed range and ranges from 1 to $2 \%$.

\section{Experimental procedures}

The combination of the ratios between the content of casein and spelled flour in certain ranges of values, in the middle of which are technologically significant subranges, determines the need for 16 experiments (Table 2).

The error estimate for the approximating polynomials (5)-(7) was determined by the formula:

$$
\sigma=\sqrt{\frac{\sum_{i=1}^{n}\left(y_{i}-\hat{y}_{i}\right)^{2}}{n-1}},
$$


where $\hat{y}_{3}$ are the values, calculated using the regression equation, $y_{i}$ are the values of the experimental data.

Table 2

Values of input variable factors and output characteristics of yoghurt

\begin{tabular}{|c|c|c|c|c|c|}
\hline \multirow{2}{*}{ Sample number } & \multicolumn{2}{|c|}{ Variable factors } & \multicolumn{3}{|c|}{ Response functions } \\
\hline & Мc, \% & Ms, \% & $\mathrm{S}, \mathrm{cm}^{3} / 100 \mathrm{~g}$ & $\eta, \mathrm{mPa} s$ & OI, points \\
\hline 1 & 0 & 0 & 34.0 & 342.7 & 5.4 \\
\hline 2 & 1 & 0 & 26.0 & 452.0 & 7.2 \\
\hline 3 & 2 & 0 & 20.2 & 642.8 & 8.0 \\
\hline 4 & 3 & 0 & 15.3 & 701.1 & 8.8 \\
\hline 5 & 0 & 1 & 30.6 & 399.5 & 6.5 \\
\hline 6 & 1 & 1 & 22.4 & 522.2 & 8.5 \\
\hline 7 & 2 & 1 & 10.8 & 755.4 & 10.0 \\
\hline 8 & 3 & 1 & 9.5 & 793.8 & 9.8 \\
\hline 9 & 0 & 2 & 26.3 & 477.2 & 7.5 \\
\hline 10 & 1 & 2 & 15.4 & 638.2 & 9.4 \\
\hline 11 & 2 & 2 & 12.7 & 784.1 & 9.1 \\
\hline 12 & 3 & 2 & 9.0 & 814.7 & 8.9 \\
\hline 13 & 0 & 3 & 21.0 & 603.7 & 8.4 \\
\hline 14 & 1 & 3 & 13.4 & 723.5 & 8.8 \\
\hline 15 & 2 & 3 & 11.1 & 814.0 & 8.5 \\
\hline 16 & 3 & 3 & 8.7 & 837.2 & 8.2 \\
\hline
\end{tabular}

Note: the values of the yoghurt characteristics that meet the optimization conditions are highlighted with a dark background; the characteristics of the yogurt sample with the highest indicators are highlighted in bold

The resulting equations with the calculated coefficients have the form (10)-(12):

$$
\begin{gathered}
S=22,146-2,487 M s+0,015 M s^{2}+ \\
+1,694 M c-0,571 M c^{2}-1,109 M s M c, \\
E V=186,876+283,292 M s-34,336 M s^{2}+ \\
+181,109 M c-15,948 M c^{2}-33,663 M s M c, \\
O I=3,159+3,664 M s-0,572 M s^{2}+ \\
+3,444 M c-0,597 M c^{2}-0,716 M s M c .
\end{gathered}
$$

For the indicator of the degree of syneresis, the standard deviation is $\sigma_{c}=0,5 \mathrm{~cm}^{3 /} 100 \mathrm{~g}$, for the indicator of effective viscosity $\sigma_{e f}=10 \mathrm{mPas}$, for organoleptic indicators $\sigma_{O P}=0.3$ points, 
which indicates a rather high degree of reproducibility of the research results using the response surface.

To optimize the content of new recipe ingredients in the yoghurt, a comprehensive quality index was also used.

In accordance with the data of Table 3, Fig. 2 shows a graphical dependence of the CQI on the mass fraction of micellar casein $(M c, \%)$ and spelled flour $(M s, \%)$.

Table 3

Scaled unit values and calculated KP values

\begin{tabular}{|c|c|c|c|c|}
\hline Sample number & $\mathrm{S}, \mathrm{cm}^{3} / 100 \mathrm{~g}$ & $\eta, \mathrm{mPa} s$ & OI, points & CQI, \% \\
\hline 1 & 10.00 & 1.00 & 1.00 & 1.00 \\
\hline 2 & 7.15 & 2.99 & 4.36 & 2.99 \\
\hline 3 & 5.09 & 6.46 & 7.00 & 5.09 \\
\hline 4 & 3.35 & 7.52 & 8.06 & 3.35 \\
\hline 5 & 8.79 & 2.03 & 8.70 & 2.03 \\
\hline 6 & 5.87 & 4.27 & 9.40 & 4.27 \\
\hline 7 & 1.75 & 8.50 & 10.00 & 10.00 \\
\hline 8 & 1.28 & 9.21 & 4.60 & 1.28 \\
\hline 9 & 7.26 & 3.45 & 6.68 & 3.45 \\
\hline 10 & 3.38 & 6.38 & 8.60 & 3.38 \\
\hline 11 & 2.42 & 9.03 & 9.48 & 2.42 \\
\hline 12 & 1.11 & 9.59 & 10.00 & 1.11 \\
\hline 13 & 5.38 & 5.75 & 9.60 & 5.38 \\
\hline 14 & 2.67 & 7.93 & 9.20 & 2.67 \\
\hline 15 & 1.85 & 9.58 & 6.40 & 1.85 \\
\hline 16 & 1.00 & 10.00 & 7.82 & 1.00 \\
\hline
\end{tabular}

Fig. 2. Dependence of CQI on the content of micellar casein and spelled flour 


\section{Discussion}

In accordance with the obtained patterns, it can be concluded, that the recommended values of single quality indicators do not make it possible to determine the optimal content of casein and spelled flour in the composition of yogurt. The degree of syrenesis is not more than $15 \mathrm{~cm}^{3}$ per $100 \mathrm{~g}$ of the product, the effective viscosity is not less than $600 \mathrm{mPa} \cdot \mathrm{s}$ and not less than 9 points in the organoleptic analysis were achieved with different ranges of casein and spelled flour content. This confirms the advisability of using a complex quality indicator to obtain an objective assessment of the effect of micellar casein and spelled flour on the formation of consumer properties of yogurt.

In accordance with the results presented (Fig. 2), the values of the complex quality index $C P \geq 9$ were obtained, when micellar casein and spelled flour were added to the composition of yogurt in the following ranges:

- casein - from 1.25 to $3.0 \%$;

- spelled flour - from 0.75 to $1.50 \%$.

It should be noted, that the use of these ingredients separately does not give a high effect in comparison with their compositional use. Moreover, only the revealed optimal ratios between the components of such compositions can be recommended for practical use.

Based on the results of the study, it can be concluded, that there is a synergistic interaction between casein and spelled flour.

The practical significance of the results obtained is the developed algorithm for adjusting the chemical composition of yoghurts with increased nutritional value.

\section{Conclusions}

1. The effect of micellar casein and spelled flour on single indicators of yoghurt quality has been studied. To obtain reliable results of practical value, the expediency of using a comprehensive quality analysis in order to optimize the composition of a new type of yogurt has been proven.

2. It has been established, that it is advisable to use these ingredients in the composition of yoghurt only in a complex manner due to synergistic interaction, which makes it possible to obtain the maximum possible technological effect.

3. The optimal content of protein-containing functional and technological ingredients in the composition of yogurt with a mass fraction of $1.5 \%$ fat is the following ranges of values:

- 1.25-3.0\% - for micellar casein;

$-0.75-1.50 \%$ - for spelled flour.

\section{References}

[1] Lange, I., Mleko, S., Tomczyńska-Mleko, M., Polischuk, G., Janas, P., Ozimek, L. (2020). Technology and factors influencing Greek-style yogurt - a Review. Ukrainian Food Journal, 9 (1), 7-35. Available at: http://dspace.nuft.edu.ua/jspui/handle/123456789/31331

[2] Smirnova, I. A., Gralevskay, I. V., Afanasyeva, E. O. (2014). Technology of incubation method of yoghurt production using the short-term clot cooling stage. Tehnika i tehnologiya pishchevyh proizvodstv, 2 (33), 97-101. Available at: https://elibrary. $\mathrm{ru} / \mathrm{item} . \mathrm{asp}$ ?id=21596755

[3] Kohajdova, Z., Karovicova, J. (2008). Nutritional value and baking applications of spelt wheat. Acta Scientiarum Polonorum Technologia Alimentaria, 7 (3), 5-14. Available at: https://www.food.actapol.net/pub/1_3_2008.pdf

[4] Jankovic, S., Ikanovic, J., Popovic, V., Rakic, S., Pavlovic, S., Ugrenovic, V. et. al. (2015). Morphological and productive traits of spelt wheat - Triticum spelta L. The Journal "Agriculture and Forestry”, 61 (2). doi: HYPERLINK “https://doi.org/10.17707/ agricultforest.61.2.15" https://doi.org/10.17707/agricultforest.61.2.15

[5] Bojňanská, T., Frančáková, H. (2011). The use of spelt wheat (Triticum spelta L.) for baking applications. Plant, Soil and Environment, 48 (4), 141-147. doi: HYPERLINK “https://doi.org/10.17221/4212-pse" https://doi.org/10.17221/4212-pse

[6] Stankevych, G., Kats, A., Vasyliev, S. (2018). Investigation of hygroscopic properties of the spelt grain. Technology Audit and Production Reserves, 5 (3 (43)), 37-41. doi: HYPERLINK “https://doi.org/10.15587/2312-8372.2018.146600" https:// doi.org/10.15587/2312-8372.2018.146600 
[7] Meena, G. S., Singh, A. K., Panjagari, N. R., Arora, S. (2017). Milk protein concentrates: opportunities and challenges. Journal of Food Science and Technology, 54 (10), 3010-3024. doi: HYPERLINK “https://doi.org/10.1007/s13197-017-2796-0” https:// doi.org/10.1007/s13197-017-2796-0

[8] Nasser, S., Hédoux, A., Giuliani, A., Le Floch-Fouéré, C., Santé-Lhoutellier, V., de Waele, I., Delaplace, G. (2017). Investigation of secondary structure evolution of micellar casein powder upon aging by FTIR and SRCD: consequences on solubility. Journal of the Science of Food and Agriculture, 98 (6), 2243-2250. doi: HYPERLINK "https://doi.org/10.1002/jsfa.8711" https://doi.org/10.1002/jsfa.8711

[9] Jaynes, H. O., Pearsall, M. G., Holt, H. C. (1981). Field Test for Titratable Acidity in Milk. Journal of Dairy Science, 64 (11), 2150-2153. doi: HYPERLINK “https://doi.org/10.3168/jds.s0022-0302(81)82822-6" https://doi.org/10.3168/jds.s00220302(81)82822-6

[10] Morison, K. R., Mackay, F. M. (2001). Viscosity of lactose and whey protein solutions. International Journal of Food Properties, 4 (3), 441-454. doi: HYPERLINK “https://doi.org/10.1081/jfp-100108647” https://doi.org/10.1081/jfp-100108647

[11] Hassan, L. K., Haggag, H. F., ElKalyoubi, M. H., Abd EL-Aziz, M., El-Sayed, M. M., Sayed, A. F. (2015). Physico-chemical properties of yoghurt containing cress seed mucilage or guar gum. Annals of Agricultural Sciences, 60 (1), 21-28. doi: HYPERLINK “https://doi.org/10.1016/j.aoas.2014.11.021” https://doi.org/10.1016/j.aoas.2014.11.021

[12] Breus, N. M., Hrybkov, S. V., Polischuk, G. Y., Seidykh, O. L. (2019). Development of Mathematical Apparatus of the Expert System for Modelling Ice Cream Recipes with Specified Quality Parameters. Science and Innovation, 15 (5), 69-77. doi: HYPERLINK “https://doi.org/10.15407/scine15.05.069” https://doi.org/10.15407/scine15.05.069 